Figure 1. Treating physician's clinical suspicion for GCA before and after VUS among 431 patients without a history of GCA/aortitis

VUS positive for acute arteritis $(n=35)$

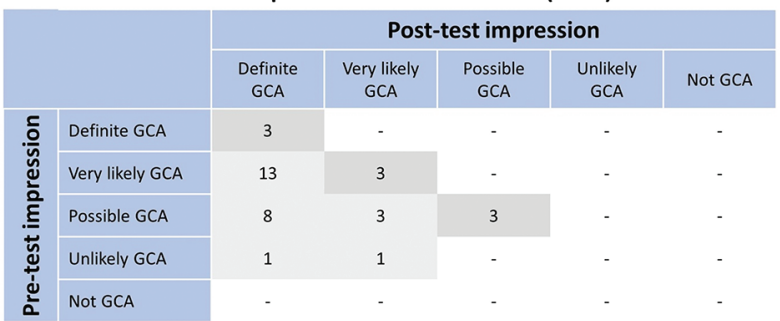

VUS negative for acute arteritis $(n=396)$

\begin{tabular}{|c|c|c|c|c|c|c|}
\hline & \multicolumn{5}{|c|}{ Post-test impression } \\
\hline & & $\begin{array}{l}\text { Definite } \\
\text { GCA }\end{array}$ & $\begin{array}{c}\text { Very likely } \\
\text { GCA }\end{array}$ & $\begin{array}{c}\text { Possible } \\
\text { GCA }\end{array}$ & $\begin{array}{l}\text { Unlikely } \\
\text { GCA }\end{array}$ & Not GCA \\
\hline \multirow{5}{*}{ 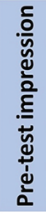 } & Definite GCA & 1 & - & - & 1 & - \\
\hline & Very likely GCA & 4 & 9 & 7 & 9 & 5 \\
\hline & Possible GCA & 3 & 2 & 35 & 41 & 141 \\
\hline & Unlikely GCA & - & - & 2 & 20 & 99 \\
\hline & Not GCA & - & 1 & - & 2 & 14 \\
\hline & Increased suspicion & \multicolumn{3}{|c|}{ No change } & \multicolumn{2}{|c|}{ Decreased suspicion } \\
\hline
\end{tabular}

Abstract THU0300 - Figure 1

Disclosure of Interests: None declared DOI: 10.1136/annrheumdis-2019-eular.1471

\section{THU0301 SPLENIC INVOLVEMENT IS NOT RARE IN ANCA- ASSOCIATED VASCULITIS HOWEVER SPLENIC INFARCT MIGHT ONLY BE ASSOCIATED WITH GRANULOMATOSIS WITH POLYANGIITIS}

Önay Gerçik ${ }^{1}$, Şebnem Karasu ${ }^{2}$, Dilek Solmaz ${ }^{1}$, Zeki Soypaçacı ${ }^{3}$,

Fulya Çakalağaoğlu ${ }^{4}$, Servet Akar ${ }^{1} .{ }^{1}$ Izmir Katip Celebi University Faculty of Medicine, Rheumatology, Izmir, Turkey, ${ }^{2}$ Izmir Katip Celebi University Faculty of Medicine, Radiology, Izmir, Turkey; ${ }^{3}$ Izmir Katip Celebi University Faculty of Medicine, Nephrology, Izmir, Turkey; ${ }^{4}$ Izmir Katip Celebi University Faculty of Medicine, Pathology, Izmir, Turkey

Background: Anti-neutrophil cytoplasmic antibody (ANCA) associated vasculitis (AAV) is a systemic necrotizing vasculitis of small and mediumsized arteries. Although, upper and lower respiratory tracts and kidneys are predominantly affected; other organs/systems can also be involved in the course of the disease and in some cases, it might be difficult to differentiate subgroups based on the clinical presentation. Splenic involvement has been rarely reported, mainly in patients with granulomatosis with polyangiitis (GPA), in fact, it was thought to be underestimated, as it is often asymptomatic.

Objectives: In this study, we aimed to investigate systematically the frequency of splenic infarct and related factors in our AAV patients. We also evaluated the role of splenic involvement in the differentiation of AAV subgroups.

Methods: Patients with a diagnosis of AAV in whom abdomen/thorax computed tomography (CT) was performed were included in the study. An experienced radiologist examined CT images for the presence of splenic involvement. The clinical and demographic data were retrospectively collected.

Results: In total 70 (30 [43\%] female and mean age $56.1 \pm 15.7$ years) AAV patients (38 [54\%] had granulomatosis with polyangiitis (GPA); 20 [29\%] microscopic polyangiitis; 11 [16\%] renal-limited disease and 1 [1\%] eosinophilic granulomatosis with polyangiitis) were included in the analysis. Splenic pathologies including splenomegaly, hypodense lesion/s, lobulation, and infarction were seen in $21(30 \%)$ patients with AAV. Splenic infarct was observed in seven (10\%) patients and all had GPA with renal involvement and PR3ANCA positive. Three of them had total splenic infarct or auto-splenectomy. None of these patients had a history of endocarditis, shock or malignancy before CT. Splenic infarction was found to be negatively correlated with age at diagnosis $(p=0.017$; rho $=-0.285)$, and positively associated with ENT (ear-nose-throat) $(p=0.002$; rho $=0,370)$ and eye involvements $(p=0.013$; rho $=0,324)$
Conclusion: Our results show that splenic pathologies might not be rare in AAV however, infarction can help to separate GPA from other AAVs. In young GPA patients, in particular, those with ENT and eye involvement, physicians should remember splenic infarction. Since almost half of our cases had severe infarction or autosplenectomy, clinicians might con sider immunization in GPA patients for vaccine-preventable infections.

\section{REFERENCES:}

[1] Fishman D, Isenberg DA. Splenic involvement in rheumatic diseases. Semin Arthritis Rheum. 1997;27(3):141-55

[2] Ghinoi A, Pipitone N, Cavazza A, Boiardi L, Salvarani C. Wegener granulomatosis with spleen infarction: case report and review of the literature. Semin Arthritis Rheum. 2008;37(5):328-33

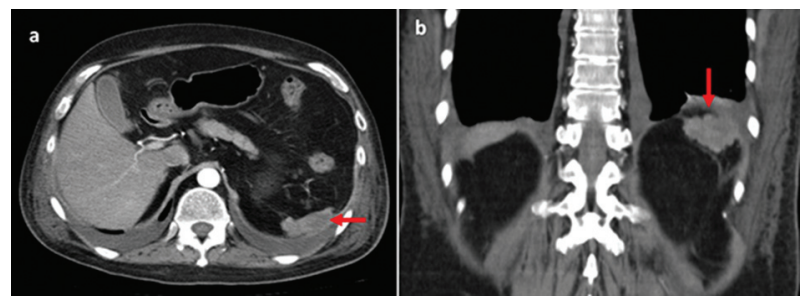

Abstract THU301 - Figure 1. Computed abdominal tomography scan of one the patients with splenic infarction; transverse (a) and coronal images (b) show an irregular contoured shrunken spleen (arrows).

Disclosure of Interests: Önay Gerçik: None declared, Şebnem Karasu: None declared, Dilek Solmaz: None declared, Zeki Soypaçacı: None declared, Fulya Çakalağaoğlu: None declared, Servet Akar Grant/research support from: MSD, Abbvie, Roche, UCB, Novartis, Pfizer, Amgen, Consultant for: MSD, Abbvie, Roche, UCB, Novartis, Pfizer, Amgen, Speakers bureau: Pfizer

DOI: 10.1136/annrheumdis-2019-eular.2745

\section{THU0302 OUTCOMES OF PREGNANCY IN BEHCET'S DISEASE}

Zemfira Alekberova ${ }^{1}$, Regina Goloeva ${ }^{2}$, Alexander Lila ${ }^{2}{ }^{1}$ V.A. Nasonova Research Institute of Rheumatology, Moscow, Russia., Moskow, Russian Federation; ${ }^{1}$ V.A. Nasonova Research Institute of Rheumatology, Moscow, Russia., Moskow, Russian Federation

Background: Behcet's disease (BD) is multisystemic disease of unknown cause. The relationship between BD and pregnancy is reported in limited number of studies.

Objectives: To evaluate outcomes of pregnancies in BD patients (pts). Methods: We retrospectively collected data of 22 women with BD diagnosis (according to ISGBD 1990 and ICBD 2014) and their 68 pregnancies. Pts' mean age was $30[26 ; 35]$ yrs, disease duration 7 [2;10] yrs. Ten $(45,5 \%)$ pts had severe $\mathrm{BD}$ according to Ch.Zouboulis classification (due to generalized uveitis, retinal vasculitis and parenchymatous CNS lesions), while other $10(45,5 \%)$ pts had mild disease with mainly dermal-mucous manifestations, and remaining two (9\%) pts had moderate disease. These patients did not receive cytotoxic therapy.

Results: Sixty-eight pregnancies in 22 pts resulted in 45 live birth (4 cesarean section in 2 pts). Four patients had 11 medical abortions on request before 12 weeks of gestation, one patient - due to medical reasons (rubella on the $7^{\text {th }}$ week of gestation). Seven $(32 \%)$ out of 22 pts had adverse pregnancy outcomes. Five (23\%) pts had 8 intrauterine deaths: one patient -3 intrauterine deaths (4-10 weeks), two pts - 2 (10-12 weeks) and one -1 intrauterine deaths (10 weeks). Two (9\%) pts had 3 miscarriages $5-10$ weeks. Antiphospholipid syndrome was never detected in pts from this cohort.

BD Severity and pathology of pregnancy

\begin{tabular}{lcc}
\hline BD Severity & $\mathrm{N}=22(\%)$ & Intrauterine deaths/Miscarriage \\
\hline Mild & $10(45,5)$ & $3 / 2$ \\
Moderate & $2(9)$ & $5 / 0$ \\
Severe & $10(45,5)$ & $0 / 1$ \\
\hline
\end{tabular}

Out of 45 babies children born by BD patients only two had relapsing aphthous stomatitis and one - congenital glaucoma ("Neurobehcet" inherited from mother).

Conclusion: BD pts demonstrated high rates of adverse pregnancy outcomes. Unfavorable outcomes of pregnancy were documented in pts regardless (with all grades of) BD severity. 